\title{
Editorial
}

http://dx.doi.org/10.34181/rbg.2018.v1n1.p1-2.32

\section{De simmer à efervescência: a produção científica em Gastronomia}

From simmer to boil: the scientific production in Gastronomy

A Gastronomia tem se apresentado como um campo em franca expansão. Da gestão ao resgate de saberes e fazeres tradicionais; do empreendedorismo às mudanças de hábitos e inovações tecnológicas; do envolvimento da sociedade à formação acadêmica. O crescimento refletiu na oferta de cursos em Gastronomia, nas modalidades bacharelado ou tecnólogo. Em cerca de quinze anos o cenário brasileiro passou de 01 instituição de ensino superior no final dos anos 1990, para cerca de 155 em 2016, segundo dados do MEC/INEP, refletindo também na oferta de cursos de extensão e pós-graduação lato sensu em áreas correlatas.

A produção científica é ainda um campo a se explorar em Gastronomia. Mendes e Faleiros (2013) avaliaram o ensino da pesquisa científica em cursos superiores de Tecnologia em Gastronomia no estado de São Paulo (estado com maior oferta do curso) e constataram que as instituições pouco direcionam seus discentes para a pesquisa, restringindo o contato, muitas vezes, com a disciplina de Metodologia Científica e de Projeto. Como solução apontam o incentivo aos docentes à pesquisa, direcionando a formação para um profissional apto a garantir seu contínuo aprendizado, inclusive prosseguindo em estudos de pós-graduação.

Hoje a pesquisa em nível de pós-graduação da temática está concentrada em programas de Turismo e Hospitalidade ou ligados às áreas da Nutrição, História ou Sociologia, por exemplo (RUBIM; REJOWSKI, 2013). No Diretório dos Grupos de Pesquisa do Brasil, do CNPq, o termo "gastronomia" está presente como palavra-chave em linha de pesquisa em cerca de 54 grupos de pesquisa certificados pela instituição (CNPq, 2018). Já o catálogo de teses e dissertações da Capes a busca por "gastronomia" resulta em 361 resultados, sendo a maioria de dissertações.

É nesse contexto de incentivo à pesquisa que nasce a RBG - Revista Brasileira de Gastronomia, como um espaço para divulgação e compartilhamento de pesquisas na área. Abrir um campo para expor as dúvidas e incertezas e contestar teorias, fórmulas e premissas permite a busca e o avanço do conhecimento na pesquisa, ensino e extensão (BUARQUE, 1994 apud MENDES; FALEIROS, 2013).

A alimentação - ato cultural e social - influencia fatores ecológicos, históricos, econômicos e culturais, estabelecendo-se, assim, como uma área multidisciplinar. Esta primeira edição apresenta artigos de pesquisadores das áreas da Sociologia, Antropologia, História, Nutrição e Química, de institutos educacionais de diversas regiões do país.

O lançamento da RBG está contemplado na programação do evento 31 Encatho e Exprotel "Interfaces hoteleiras: nem só de cama e café vive um hotel", realizado em 25 de julho de 2018 no Centrosul, Florianópolis, sob a coordenação da Associação Brasileira da Indústria de Hoteis de Santa Catarina (ABIH-SC) e apoio do Senac Santa Catarina.

O primeiro texto, "O gosto do popular: dinâmicas globais e as cozinhas tradicionais", de Kadma Marques Rodrigues e Filipe Pessoa Camelo, traz a reflexão da gastronomia a partir de um viés popular, não apenas categorizado como regional, a partir do registro da diferença.

Raul Lody, em "Dendê: com a África à boca", apresenta pesquisas de campo realizadas no Brasil e em países africanos, que formam a base etnográfica das muitas relações entre ambos e a criação de acervos 
patrimoniais únicos, sobretudo através do azeite de dendê. O seu significado na economia, na religiosidade e na gastronomia, representando uma identidade de matriz africana no Brasil.

Em "Desenvolvimento de sobremesas contemporâneas com base na diversidade brasileira", as pesquisadoras Fabiana Mortimer Amaral, Alice Nogueira Novaes Southgate e Érika Arcaro Bez Batti apresentam o desenvolvimento de sobremesas contemporâneas através da valorização de saberes e fazeres tradicionais, demonstrando as possibilidades de criação a partir da valorização dos produtos locais e técnicas tradicionais.

Produção artesanal de queijos é o assunto abordado por Andréa Carla Mendonça de Souza Paiva no artigo "A regulamentação de queijos artesanais: algumas reflexões". Apresenta um histórico sobre o sistema agroindustrial do leite, os serviços de inspeção sanitária no Brasil e a importância da regulamentação dos produtos artesanais para proporcionar mudanças econômicas, políticas e sociais no país.

Finaliza este número o artigo de Sidiana da Consolação Ferreira de Macêdo, "Menu de Madame: influências lusitanas na alimentação em Belém", que analisa o receituário Menu de Madame publicado na década de 1950 no jornal da cidade e a maneira que as práticas alimentares de Belém tiveram contribuições lusitanas a partir de trocas culturais proporcionada pelo processo de imigração.

Uma fotografia conta uma história; a que ilustra a capa da primeira edição da Revista Brasileira de Gastronomia vem representar a mandioca e os engenhos de farinha da llha de Santa Catarina. É nossa forma de homenagear a cidade que nos "acolhe". O registro foi feito pela fotógrafa Vanessa Alves, durante a tradicional Farinhada no Engenho da Vila Verde, na Lagoa da Conceição, Florianópolis, um dos engenhos de farinha de mandioca remanescentes na llha de Santa Catarina.

Desejamos uma boa leitura e que este periódico suscite novas reflexões na construção de um pensar científico e crítico da área, fortalecendo assim a Gastronomia enquanto ciência.

Florianópolis, 25 de julho de 2018.

Nathália Bernardinetti Editora-Gerente Revista Brasileira de Gastronomia

\section{REFERÊNCIAS}

INSTITUTO NACIONAL DE ESTUDOS E PESQUISAS ANÍSIO TEIXEIRA. Sinopse Estatística da Educação Superior 2016. Brasília: Inep, 2017. Disponível em: <http://portal.inep.gov.br/web/guest/sinopses-estatisticas-da-educacao-superior>. Acesso em 28 mar. 2018.

MENDES, Bruna Castro; FALEIROS, Pedro Bordini. O ensino da pesquisa científica em cursos superiores de Tecnologia em Gastronomia. Revista Hospitalidade. São Paulo, v. X, n. 1, p. 121 - 146, jun. 2013. Disponível em:

<https://www.revhosp.org/hospitalidade/article/view/509/533>. Acesso em: 28 mar. 2018.

MUELLER, S. P. M. O periódico científico. In: CAMPELLO, B. S.; CÉNDON, B. V.; KREMER, J. M. (Org.). Fontes de informação para pesquisadores e profissionais. Belo Horizonte: UFMG, 2003. p. 73-96.

RUBIM, Rebeca Elster; REJOWSKI, Mirian. O ENSINO SUPERIOR DA GASTRONOMIA NO BRASIL: ANÁLISE DA REGULAMENTAÇÃO, DA DISTRIBUIÇÃO E DO PERFIL GERAL DE FORMAÇÃO (2010-2012). Turismo, Visão e Ação, Balneário Camboriú, v. 15, n. 2, p.166-184, ago. 2013. Disponível em: <https://siaiap32.univali.br/seer/index.php/rtva/article/view/3781/2611>. Acesso em: 28 mar. 2018. 